\title{
Co-Occurrence of Multiple Endocrine Abnormalities Induced by the DIHS/DRESS
}

\author{
Mingqun Deng $\left(\mathbb{D}\right.$, Han Wu, Miao Yu $\left(\mathbb{D}\right.$, Yi Tian, Yuxiu Li $\mathbb{D}^{D}$, and Xinhua Xiao $\mathbb{C}$ \\ Department of Endocrinology, Key Laboratory of Endocrinology, Ministry of Health, Peking Union Medical College Hospital, \\ Peking Union Medical College and Chinese Academy of Medical Sciences, Beijing 100730, China
}

Correspondence should be addressed to Miao Yu; yumiao_lisa@pumch.cams.cn

Received 18 March 2019; Revised 14 August 2019; Accepted 7 September 2019; Published 3 October 2019

Academic Editor: Basilio Pintaudi

Copyright $($ C 2019 Mingqun Deng et al. This is an open access article distributed under the Creative Commons Attribution License, which permits unrestricted use, distribution, and reproduction in any medium, provided the original work is properly cited.

Background. Drug-induced hypersensitivity syndrome/drug reaction with eosinophilia and systemic symptoms (DIHS/DRESS) is a severe adverse reaction caused by specific drugs. However, little information is available about sequelae following DIHS/DRESS resolution from an endocrinologist's perspective. This study aimed to investigate the endocrine sequelae following DIHS/DRESS, from clinical feature to etiology. Methods. We retrospectively analyzed the patients diagnosed with DIHS/DRESS in Peking Union Medical College Hospital (PUMCH) during the period of 1 January 2012 to 31 December 2017, and those who developed endocrine disorders after DIHS/DRESS were further examined. We also reviewed the literature, from 1 January 2000 to 31 December 2017, on involvement of endocrine glands in DIHS/DRESS patients. Results. Three patients developed both autoimmune thyroid disease (AITD) and type 1 diabetes (T1DM)/fulminant type 1 diabetes (FT1DM) of the 45 patients. Seven cases involving more than two endocrine glands were reported in the literature. Our results indicated that DIHS/DRESS is a potential etiological factor of autoimmune polyendocrine syndrome (APS), especially APS III. Conclusions. Patients require careful longterm follow-up after DIHS/DRESS. Involvement of endocrine glands, especially FT1DM, should always be monitored in patients with a history of DIHS/DRESS. This study indicated that DIHS/DRESS could lead to APS, especially APS III, providing novel insights into the etiological factors of APS.

\section{Background}

The drug-induced hypersensitivity syndrome/drug reaction with eosinophilia and systemic symptoms (DIHS/DRESS) is a severe adverse drug reaction. A growing number of reports have documented the occurrence of newly developed diseases after DIHS/DRESS resolution, especially autoimmune diseases such as type 1 diabetes mellitus (T1DM) [1-4] and autoimmune thyroid disease (AITD) [5-8]. Following DIHS/ DRESS, fulminant type 1 diabetes mellitus (FT1DM) has been reported more often than typical T1DM. The rapid and destructive onset of FT1DM should be paid great attention. More than one autoimmune disease involving endocrine glands can co-occur in the same patient, a condition referred to as autoimmune polyendocrine syndrome (APS). However, little attention has been paid by endocrinologists to this ailment. Here, we report 3 patients with co-occurrence of FT1DM and AITD.

\section{Methods}

We reviewed the medical records of all inpatients diagnosed with DIHS/DRESS in PUMCH between 1 January 2012 and 31 December 2017. The diagnostic criteria of DRESS used in this study were proposed by European Registry of Severe Cutaneous Adverse Reactions (RegiSCAR) [9]. In January 2018, we obtained the current medical history for all patients through phone calls. Patients with suspected endocrine disorders after DIHS/DRESS were readmitted for further investigation. Follow-up data, including clinical records, physical examination, and routine laboratory examination, were obtained.

A review of the published literature on endocrine abnormalities induced by DIHS/DRESS was performed. The key terms "Drug-induced Hypersensitivity Syndrome," "Drug-induced Hypersensitivity Syndromes," "Drug Reaction with Eosinophilia and Systemic Symptoms," "Drug Hypersensitivity 
Syndromes," "Hypersensitivity Syndrome, Drug," "Hypersensitivity Syndromes, Drug," "Syndrome, Drug Hypersensitivity," "Syndromes, Drug Hypersensitivity," "DRESS Syndrome," "DRESS Syndromes," "Drug Reaction with Eosinophilia and Systemic Symptoms Syndrome," "Autoimmune Thyroid Disease," "AITD," "Thyroiditis," "Diabetes," "Diabetes Mellitus," and "DM" were used to search PUBMED for publications written in English on human subjects from 1 January 2000 to 31 December 2018. Studies reporting patients with more than one endocrine abnormality after DIHS/DRESS were included.

\section{Results}

Forty-five patients were diagnosed as DIHS/DRESS in our hospital during 1 January 2012 to 31 December 2017. Four individuals described that they were diagnosed with endocrine gland damage after DIHS/DRESS, and the other forty-one patients denied any symptoms of hyperglycemia, hypothyroidism, adrenal insufficiency, or hypopituitarism. One patient developed hypothyroidism, and the other three patients were diagnosed with both T1DM and Hashimoto's thyroiditis (HT). The patient with only hypothyroidism declined further investigation; the other three patients were readmitted into our department. All the three patients were demonstrated to be both T1DM (including FT1DM) and HT at readmission as presented below (Table 1). Comparing with the other forty-two patients, the average age of the three patients seemed younger $(22.5 \pm 3.4$ vs $18.9 \pm 6.0, P=0.074)$. No gender preference was revealed as the percentage of female patients was $55.6 \%$ and $70 \%(P=0.494)$, respectively.

3.1. Case 1. In March 2016, after treatment with nonsteroidal anti-inflammatory drugs (NSAIDs) and antibiotics, a 25-yearold male patient gradually experienced fever $\left(39.8^{\circ} \mathrm{C}\right)$, with morbilliform rashes, facial edema, and generalized erythema (Figure 1). Laboratory tests showed hypereosinopenia, liver dysfunction, and acute kidney injury. Ultrasound indicated inguinal lymph node enlargement, while skin biopsy revealed exfoliative dermatitis. With irregular use of systemic glucocorticoid for about one month, which was starting with intravenous infusion of methylprednisolone $80 \mathrm{mg}$ for one day and then $40 \mathrm{mg}$ for two days, he gradually recovered. However, he was admitted to the Emergency Room of PUMCH because of severe ketoacidosis in May after discontinuing prednisone for 2 days. Laboratory analysis showed artery blood gas (ABG) of pH 7.064, plasma glucose of $42.4 \mathrm{mmol} / \mathrm{L}$, glycated hemoglobin (HbA1c) of $7.8 \%$, and fasting $\mathrm{C}$ peptide $<0.05 \mathrm{ng} / \mathrm{ml}$. Islet cell antibodies-IgG (ICA-IgG), glutamic acid decarboxylase antibodies (GAD), and anti-insulin-associated protein-2 Antibody (IA-2Ab) were negative, and insulin autoantibody (IAA) was positive. Rubella virus-IgG (RV-IgG), RV-IgM, and CMV-IgG were found to be positive at that time. Insulin therapy was then prescribed. In January 2017, with fatigue for 1 month, he was referred to the Endocrinology Department of PUMCH. The thyroid function test indicated primary hypothyroidism with elevated antithyroid peroxidase antibodies (A-TPO), antithyroglobulin antibodies (A-Tg), and thyrotropin receptor antibodies (TRAb). Thyroid ultrasonography showed diffuse reduced echogenicity. Therefore, a clinical diagnosis of HT was made. Fatigue was significantly improved with levothyroxine replacement therapy. No involvement of other endocrine glands was found in his readmission in January 2018.

3.2. Case 2. A 33-year-old female was admitted in our department in March 2018 for further clinical investigation. In October 2015 , the patient had a fever of $38.8^{\circ} \mathrm{C}$, rashes on the whole body, kidney injury, and hepatitis, after treatment with Chinese traditional medicine (specific ingredients were unknown). She was referred to the Dermatology Department of our hospital. Parvovirus B19 IgM was positive at that time. A diagnosis of DIHS/DRESS was made, and intravenous infusion of methylprednisolone ( $40 \mathrm{mg}$ every day) was prescribed. In December 2015, her plasma glucose was normal. However, she suffered from nausea, vomiting, and abdominal pain in January 2016. ABG showed pH of 7.188, with plasma glucose of $33.0 \mathrm{mmol} / \mathrm{L}, \mathrm{HbA} 1 \mathrm{c}$ of $10.58 \%$, and positive ketone bodies in urine. She began insulin therapy since then, with no more prednisone. In the further investigation in March 2018, laboratory examinations showed fasting $\mathrm{C}$ peptide and $2 \mathrm{~h}$ postprandial $\mathrm{C}$ peptide were all below $0.05 \mathrm{ng} / \mathrm{mL}$. ICA-IgG and IA-2Ab were negative, while $\mathrm{GAD}$ was $>2000 \mathrm{U} / \mathrm{ml}$. IAA was positive, with a titer of $4.63 \mathrm{U} / \mathrm{ml}$. The thyroid function test was normal, with overtly elevated A-TPO and A-Tg. Thyroid ultrasound showed inhomogeneous internal echoes with regions of reduced echogenicity, as well as a thyroid solid nodule with microcalcification. Fine-needle aspiration biopsy (FNAB) indicated papillary thyroid carcinoma (PTC).

3.3. Case 3. A 25-year-old woman was referred to the dermatology department of our hospital in June 2017. After taking oxcarbazepine for about 1 month, she suffered from a fever of $39^{\circ} \mathrm{C}$, facial edema, and erythema gradually developing to the whole body. Laboratory tests indicated hypereosinopenia and atypical lymphocytes in peripheral blood. Elevated alanine transaminase (ALT) and aspartate aminotransferase (AST) indicated liver injury, while the kidney was spared. RV-IgG, CMV-IgG, and HSV-1-IgG were positive. Diagnosis of DIHS/DRESS was made by the dermatologist, and treatment with glucocorticoid was initiated as the following: intravenous infusion of methylprednisolone (40 mg every day) for five days was prescribed and then oral prednisone. While the abovementioned symptoms faded, she presented to the emergency department because of diabetic ketoacidosis (DKA) in October 2017. For further care, she was referred to our department in December 2017. HbA1c was $8.6 \%$, with fasting $\mathrm{C}$ peptide and $2 \mathrm{~h}$ postprandial $\mathrm{C}$ peptide below detectable levels, ICA-IgG and IA-2Ab were negative, and GAD was positive with a low titer. IAA was also positive, with a titer of $22.22 \mathrm{IU} / \mathrm{mL}$. After admission in our department in March 2018, thyroid function was normal with overtly elevated levels of A-TPO and A-Tg. 
TABLe 1: Three cases of co-occurrence of FT1DM and HT in PUMCH during January 2012 to December 2017.

\begin{tabular}{|c|c|c|c|c|}
\hline & & Case 1 & Case 2 & Case 3 \\
\hline Age & & 25 & 33 & 25 \\
\hline Gender & & Male & Female & Female \\
\hline \multirow{6}{*}{ DIHS/DRESS syndrome } & Causative drugs & Unknown & Unknown & Oxcarbazepine \\
\hline & Fever $>38.5^{\circ} \mathrm{C}$ & Yes & Yes & Yes \\
\hline & Rashes & Yes & Yes & Yes \\
\hline & Eosinophils & $1.45 \times 10^{9} / \mathrm{L}$ & $5.45 \times 10^{9} / \mathrm{L}$ & $0.74 \times 10^{9} / \mathrm{L}$ \\
\hline & Other organs & ALT 301 U/L, & ALT $206 \mathrm{U} / \mathrm{L}$ & ALT $273 \mathrm{U} / \mathrm{L}$ \\
\hline & involvement & $\mathrm{Cr} 485 \mu \mathrm{mol} / \mathrm{L}$ & $\mathrm{Cr} 181 \mu \mathrm{mol} / \mathrm{L}$ & AL1 $27 J U / \mathrm{L}$ \\
\hline
\end{tabular}

Systemic corticosteroid therapy (mg/day) or IVIG

\section{Irregular use of systemic} glucocorticoid for one month (started with methylprednisolone $80 \mathrm{mg}$ iv qd)

\begin{tabular}{|c|c|c|c|c|}
\hline \multirow{9}{*}{ Diabetes mellitus } & Diagnosis & FT1DM & T1DM & FT1DM \\
\hline & Interval of time ${ }^{\#}$ & 2 months & 3 months & 4 months \\
\hline & Onset by DKA & Yes & Yes & Yes \\
\hline & HbAlc (\%) & $7.8 \%$ & $10.58 \%$ & $8.6 \%$ \\
\hline & $\begin{array}{l}\text { Fasting C peptide } \\
(\mathrm{ng} / \mathrm{mL})\end{array}$ & $<0.05$ & $<0.05$ & $<0.05$ \\
\hline & $\mathrm{IA}-2 \mathrm{Ab}(\mathrm{IU} / \mathrm{mL})$ & 0.57 & 0.87 & 0.57 \\
\hline & ICA-IgG & Negative & Negative & Negative \\
\hline & GAD (IU/mL) & 2.33 & $>2000$ & 6.00 \\
\hline & IAA* $^{*}(\mathrm{IU} / \mathrm{mL})$ & 11.26 & 4.63 & 22.22 \\
\hline \multirow{5}{*}{$\begin{array}{l}\text { Autoimmune thyroid } \\
\text { disease }\end{array}$} & Diagnosis & HT & HT, PTC & HT \\
\hline & Interval of time & 9 months & 53 months & 9 months \\
\hline & $\begin{array}{c}\text { Thyroid function } \\
\text { test }\end{array}$ & Primary hypothyroidism & Normal & Normal \\
\hline & A-Tg (IU/ml) & 18.00 & 494.60 & 278.60 \\
\hline & A-TPO (IU/ml) & 73.50 & $>600.00$ & 150.40 \\
\hline \multirow{2}{*}{$\begin{array}{l}\text { Hypothalamic-pituitary- } \\
\text { adrenal axis }\end{array}$} & $\begin{array}{c}\mathrm{ACTH}(8 \mathrm{AM})(\mathrm{pg} / \\
\mathrm{ml})\end{array}$ & 35.2 & ND & 24.4 \\
\hline & $\begin{array}{c}\text { Cortisol (8AM) } \\
(\mu \mathrm{g} / \mathrm{dl})\end{array}$ & 18.35 & ND & 15.11 \\
\hline \multirow{2}{*}{ GH-IGF1 axis } & $\mathrm{GH}(\mathrm{ng} / \mathrm{ml})$ & 0.1 & ND & ND \\
\hline & IGF1 (ng/ml) & 252 & 205 & 236 \\
\hline \multirow{3}{*}{ Gonadal hormone } & LH (IU/L) & 7.64 & 11.66 & 4.18 \\
\hline & FSH (IU/L) & 23.35 & 23.54 & 10.07 \\
\hline & $\begin{array}{c}\mathrm{T}(\mathrm{ng} / \mathrm{ml}) \text { or } \mathrm{E} 2 \\
(\mathrm{pg} / \mathrm{ml})\end{array}$ & 4.94 & 45.29 & 59.93 \\
\hline Hypoparathyroidism & & No & No & No \\
\hline
\end{tabular}

ND: no data. ${ }^{*}$ Measured by the radioligand-binding assay (RBA); ${ }^{*}$ the resolution of DIHS/DRESS and the onset of DM or AITD. Normal range: IA-2Ab 0.00-1.00 IU/mL; GAD 0.00-5.00 IU/mL; IAA 0.00-0.40 IU/mL; A-Tg < $115 \mathrm{IU} / \mathrm{mL} ; \mathrm{A}-\mathrm{TPO}<34 \mathrm{IU} / \mathrm{mL}$.

Thyroid ultrasound showed inhomogeneous internal echoes with solid nodules.

3.4. Literature Review. Studies published between 1 January 2000 and 31 December 2017 were reviewed. A total of 7 cases involved more than two endocrine glands [6, 10-14] (Table 2). Of the 7 cases, 3 were FT1DM and 4 were typical T1DM. Although 1 case was diagnosed as thyroiditis with A-TPO, A-Tg, or thyroid-stimulating immunoglobulin (TSI) undetected, the remaining 6 were definite AITD.

\section{Discussion}

DIHS/DRESS is a severe adverse drug reaction. Various medications have been described to cause DIHS/DRESS; phenytoin and allopurinol are the two most common culprit drugs. DIHS/DRESS is characterized by rashes, fever, hypereosinopenia, lymph node enlargement, and visceral involvement (liver, lung, kidney, etc.) [15]. There is no diagnostic standard of DIHS/DRESS, and the diagnostic criteria from Europe and Japan are widely used in clinical practice $[15,16]$. In Asia, the DIHS/DRESS represents almost one tenth of all adverse drug reaction cases, with a mortality rate of $3-10 \%$ [17-20]. Various newly developed autoimmune diseases are considered sequelae of the DIHS/DRESS, including thrombotic thrombocytopenic purpura (TTP) [21], autoimmune hemolytic anemia (AHA) [22], sclerodermoid graft-versus-host disease-like lesions [23], and systemic lupus erythematosus (SLE) [24]. FT1DM is one of the most important sequelae of DIHS/DRESS. It has been reported to 


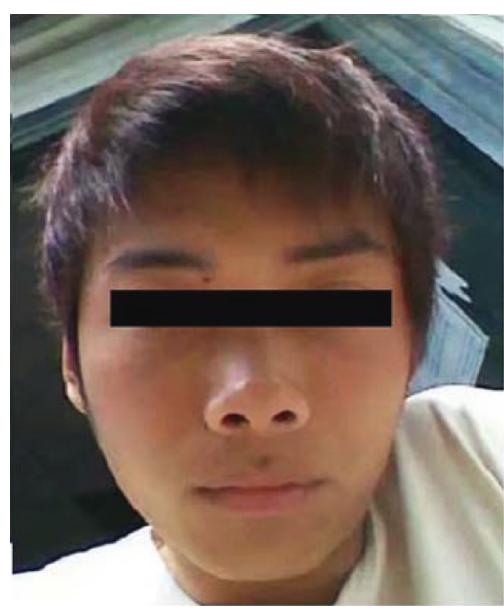

(a)

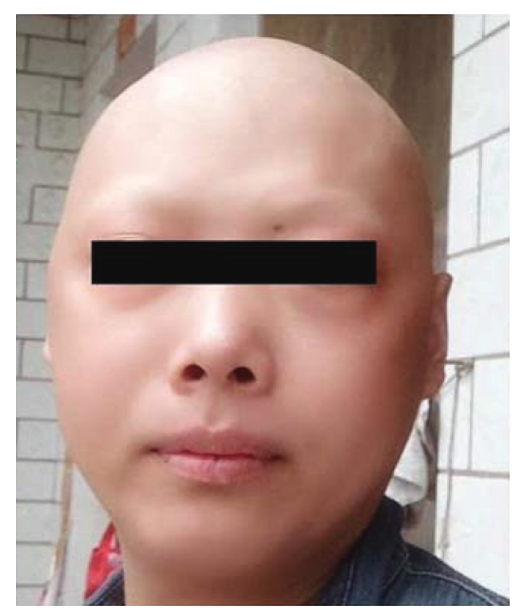

(b)

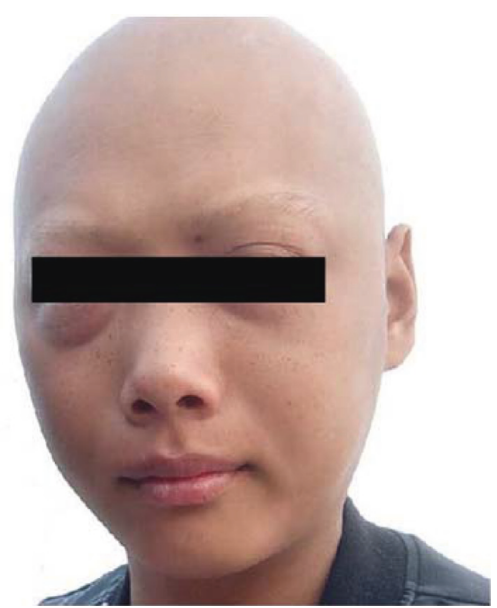

(c)

Figure 1: Case 1, 25-year-old male. (a) Before DIHS/DRESS; (b) July 2016, 4 months after DIHS/DRESS, the patient had no hair in the whole body; (c) September 2016, 6 months after DIHS/DRESS, eyebrow began to grow.

occur at intervals of 39.9 days averagely after clinical resolution of the DIHS/DRESS [4]. According to the Committee of the Japan Diabetes Society, FT1DM is confirmed when all the following three findings are present [25]: (1) occurrence of diabetic ketosis or ketoacidosis soon (approximately 7 days) after the onset of hyperglycemic symptoms (elevation of urinary and/or serum ketone bodies at the first visit); (2) plasma glucose level $\geq 16.0 \mathrm{mmol} / \mathrm{L}(\geq 288 \mathrm{mg} / \mathrm{dL})$ and glycated hemoglobin level $<8.7 \%$ (NGSP value) at the first visit; (3) urinary C-peptide excretion $<10 \mu \mathrm{g} /$ day or fasting serum C-peptide level $<0.3 \mathrm{ng} / \mathrm{mL}(<0.10 \mathrm{nmol} / \mathrm{L})$ and $<0.5 \mathrm{ng} / \mathrm{mL}$ $(<0.17 \mathrm{nmol} / \mathrm{L})$ after intravenous glucagon (or after meal) load at onset. Case 1 and Case 3 could be definitely be diagnosed as FT1DM. In the current cases, FT1DM occurred between 2 and 4 months in all cases, with rapid onset of DKA. FT1DM usually occurs long time after recovery from the DIHS/DRESS and could be easily ignored without special attention from clinicians. However, its abrupt onset requires prompt intervention. Therefore, patients with DIHS/DRESS should be followed up carefully. Meanwhile, elevated thyroidrelated autoantibodies were observed in all three patients. Combined with features on the ultrasound, the three patients were clinically diagnosed as HT. HT is one of the most common AITD. According to the previous studies and our cases, AITD occurs at intervals of several months to years after clinical resolution of DIHS/DRESS [26].

Regulatory T cells (Tregs), with high expression levels of CD4, CD25, and forkhead box P3 (FoxP3), are a special T-cell subpopulation, which suppresses the immune system. Actually, Tregs have been well documented to play crucial physiological roles in preventing the development of autoimmune diseases and maintaining self-tolerance [27]. In 2009, Takahashi et al. [28] firstly demonstrated that CD4, CD25, and FoxP3 Tregs expanded at the acute stage of the DIHS/DRESS. However, they become functionally deficient after DIHS/DRESS resolution. Viral reactivation plays an important role in Tregs dysfunction. The expansion of Tregs allows sequential reactivation of viruses, which in turn elicit repeated and excessive activation of antiviral T-cell responses. Tregs excessively activated to limit overactivation of antiviral T-cell responses might be eventually exhausted at the resolution stage [24]. A reduction in Tregs or an attenuation of their suppressive activity would free autoreactive $\mathrm{T}$ cells, which may elicit autoimmunity [29]. In conclusion, Treg dysfunction may explain why autoimmune diseases occur in patients with DIHS/DRESS, especially at the resolution stage. As for T1DM, increasing evidence indicates that Tregs play a central role in suppressing T-cellmediated immune responses as well as the development of both typical T1DM and FT1DM [30]. In 2013, Haseda et al. [31] found that CD4 (+) CD45RA (-) FoxP3 highly activated Tregs are functionally impaired in both FT1DM and typical T1DM, especially with undetectable C peptide. This corroborates the notion that FT1DM is more common than the typical T1DM as a DIHS/DRESS sequela.

APS is defined as the coexistence of two endocrine autoimmune diseases [32]. Found in $70-75 \%$ of APS patients, AITD represents the most frequent autoimmune endocrinopathy. The second most common endocrine autoimmune disease in adult APS is T1DM [33]. Combination of both diseases, without Addison's disease, is termed as APS type III which represents the most prevalent subtype [34]. Brown reported a case with co-occurrence of Graves' disease and typical TIDM after DIHS/DRESS. With two autoimmune endocrinopathies, we think the patient could be diagnosed as APS III. In other words, the DIHS/DRESS syndrome could lead to APS III. By reviewing clinical records, we found that 4 of 45 cases (8.8\%) develop autoimmune endocrine sequelae after the DIHS/DRESS. As we did not re-evaluate the endocrine system of all 45 patients, actual cases with endocrine glands involvement may be underestimated. Meanwhile, 3 of 4 cases involved more than one endocrine gland, indicating APS III does not seem to be rare in DIHS/DRESS. However, only a few cases with cooccurrence of T1DM and AITD have been reported by others. This might result from clinicians' ignorance to systemic evaluation of endocrine involvement. Although patients developed APS III seemed younger than those 


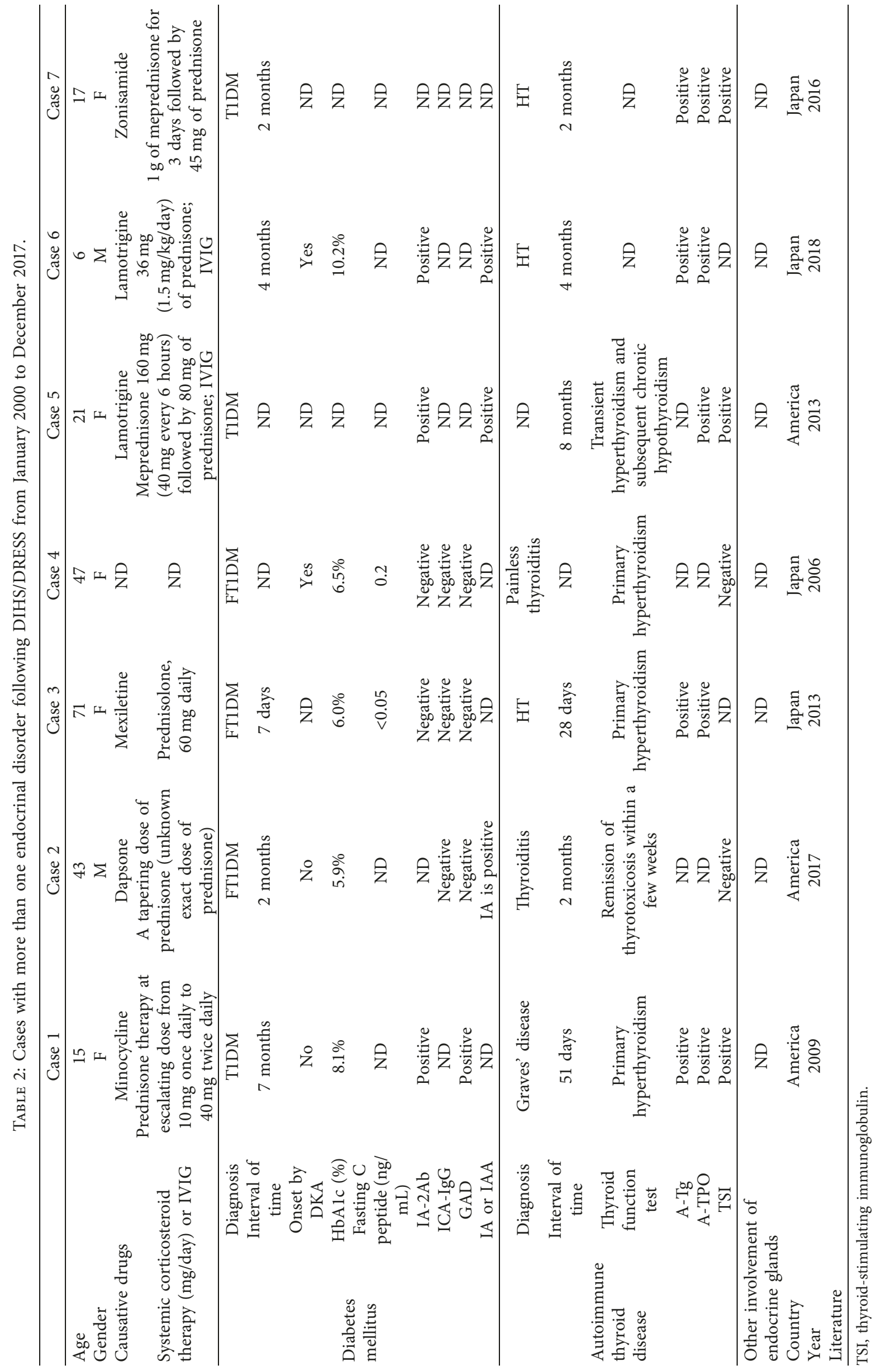


without APS III, it did not reach statistical difference. As for gender, there seemed more female patients in APS III than general DIHS/DRESS patients. However, no statistical difference reached either. It has been reported that intravenous immunoglobulin (IVIG) or pulsed prednisone can accelerate a rapid recovery of $B$ and T cells in the acute stage of DIHS/ DRESS, which might relate to the development of APS III. However, only 2 out of 7 patients in the literature were treated with IVIG, and 1 out of 7 patients were treated with pulsed prednisone. No patients who developed APS III later were treated with IVIG in the acute stage of DIHS/DRESS in our center. As discussed above, functional reduction of Tregs may contribute to autoimmune sequelae of the DIHS/DRESS syndrome. In APS III, it was found that reduced function of Tregs associated with FOXP3 genetic variants could promote the development of autoimmune endocrinopathies, especially APS III [35]. Therefore, we suppose that Tregs dysfunction bridges autoimmune sequalae of DIHS/DRESS with APS. Younger female patients with DIHS/DRESS and patients treated with pulsed prednisone or IVIG might have the greater risk for subsequently developing APS III, which needed further investigation to confirm.

There are some limitations of our study. Firstly, as most patients were from out of Beijing, we identified if patients had endocrine abnormalities through phone calls, which might result in missing cases. Secondly, some clinical information was inaccessible as a retrospective study, including serum pancreatic enzymes in the onset of FT1DM. Thirdly, we did not investigate the Tregs function in our study.

\section{Conclusions}

Patients with the DIHS/DRESS should undergo long-term monitoring for signs or symptoms suggestive of autoimmune diseases. Functional defect of Tregs after the resolution of the DIHS/DRESS may contribute to autoimmune sequelae. The present findings suggested that APS could be induced by DIHS/DRESS, especially APS III, which might be due to similar pathogenesis of Tregs. Among all autoimmune diseases, FT1DM should be extremely paid attention to, as it is not rare and may lead to severe consequences.

\section{Abbreviations}

$\begin{array}{ll}\text { DIHS/ } & \begin{array}{l}\text { The drug-induced hypersensitivity } \\ \text { syndrome/drug reaction with eosinophilia } \\ \text { DRESS: }\end{array} \\ \text { and systemic symptoms } \\ \text { PUMCH: } & \text { Peking Union Medical College Hospital } \\ \text { AITD: } & \text { Autoimmune thyroid disease } \\ \text { FT1DM: } & \text { Fulminant type } 1 \text { diabetes mellitus } \\ \text { APS: } & \text { Autoimmune polyendocrine syndrome } \\ \text { T1DM: } & \text { Type 1 diabetes mellitus } \\ \text { HT: } & \text { Hashimoto's thyroiditis } \\ \text { HbA1C: } & \text { Glycated hemoglobin } \\ \text { ABG: } & \text { Artery blood gas } \\ \text { ICA-IgG: } & \text { Islet cell antibodies-IgG } \\ \text { GAD: } & \text { Glutamic acid decarboxylase antibodies } \\ \text { IA-2Ab: } & \text { Anti-insulin-associated protein-2 antibody }\end{array}$

A-TPO: $\quad$ Antithyroid peroxidase antibodies

A-Tg: Antithyroglobulin antibodies

TRAb: Thyrotropin receptor antibodies

FNAB: $\quad$ Fine-needle aspiration biopsy

PTC: $\quad$ Papillary thyroid carcinoma

ALT: $\quad$ Alanine transaminase

AST: Aspartate aminotransferase

TSI: Thyroid-stimulating immunoglobulin

TTP: $\quad$ Thrombotic thrombocytopenic purpura

AHA: Autoimmune hemolytic anemia

SLE: $\quad$ Systemic lupus erythematosus

FoxP3: $\quad$ Forkhead box P3

Tregs: Regulatory T cells

RV-IgG: Rubella virus-IgG

RV-IgM: Rubella virus-IgM

CMV-IgG: Cytomegalovirus-IgG

HSV-1-IgG: Herpes simplex virus type 1-IgG.

\section{Data Availability}

The datasets used and/or analyzed in the current study are available from the corresponding author on reasonable request.

\section{Additional Points}

Highlights. Patients require careful long-term follow-up after DIHS/DRESS. Functional defect of Tregs dysfunction after the resolution of the DIHS/DRESS contributes to autoimmune sequelae. The present findings suggested that APS, especially APS III, could be induced by DIHS/DRESS, which might be due to similar pathogenesis of Tregs.

\section{Ethical Approval}

The study protocol was approved by the Institutional Review Board and the Ethics Committee of Peking Union Medical College Hospital (PUMCH) (Approval no. S-K519).

\section{Consent}

Informed consent was obtained from each participant.

\section{Conflicts of Interest}

All authors declare that they have no any conflicts of interest.

\section{Authors' Contributions}

Mingqun Deng and Han Wu contributed equally to this work. Deng Mingqun collected the clinical data and wrote the manuscript. Wu Han collected the clinical data and summarized the relevant literature. Tian Yi collected the clinical data. Xiao Xinhua and Li Yuxiu revised the paper. All the work was done under the instructions of Yu Miao.

\section{Acknowledgments}

This work was supported by grants from the Chinese Academy of Medical Sciences Innovation Fund for Medical 
Sciences (CIFMS2017-12M-1-008), the 2016 PUMCH Science Fund for Junior Faculty (PUMCH-2016-1.14), and the National Key R\&D Program of China (2017YFC1309603).

\section{References}

[1] N. Sekine, T. Motokura, and O. Toshihiko, "Rapid loss of insulin secretion in a patient with fulminant type 1 diabetes mellitus and carbamazepine hypersensitivity syndrome," JAMA, vol. 285, no. 9, pp. 1153-1154, 2001.

[2] L. M. Sommers and R. B. Schoene, "Allopurinol hypersensitivity syndrome associated with pancreatic exocrine abnormalities and new-onset diabetes mellitus," Archives of Internal Medicine, vol. 162, no. 10, pp. 1190-1192, 2002.

[3] C.-C. Chiou, W.-H. Chung, S.-I. Hung, L.-C. Yang, and H.-S. Hong, "Fulminant type 1 diabetes mellitus caused by drug hypersensitivity syndrome with human herpesvirus 6 infection," Journal of the American Academy of Dermatology, vol. 54, no. 2, pp. S14-S17, 2006.

[4] H. Onuma, M. Tohyama, A. Imagawa et al., "High frequency of HLA B62 in fulminant type 1 diabetes with the drug-induced hypersensitivity syndrome," The Journal of Clinical Endocrinology \& Metabolism, vol. 97, no. 12, pp. E2277E2281, 2012.

[5] R. Y. Teo, Y. K. Tay, C. H. Tan, V. Ng, and D. C. Oh, "Presumed dapsone-induced drug hypersensitivity syndrome causing reversible hypersensitivity myocarditis and thyrotoxicosis," Annals of the Academy of Medicine, Singapore, vol. 35, no. 11, pp. 833-836, 2006.

[6] R. J. Brown, I. R. Kristina, A. Henry et al., "Minocyclineinduced drug hypersensitivity syndrome followed by multiple autoimmune sequelae," Archives of Dermatology, vol. 145, no. 1, pp. 63-66, 2009.

[7] E. Funck-Brentano, T. Duong, D. Family et al., "Auto-immune thyroiditis and drug reaction with eosinophilia and systemic symptoms (DRESS) associated with HHV-6 viral reactivation," Annales de Dermatologie et de Vénéréologie, vol. 138, no. 8-9, pp. 580-585, 2011.

[8] H. Cookson, D. Creamer, and S. Walsh, "Thyroid dysfunction in drug reaction with eosinophilia and systemic symptoms (DRESS): an unusual manifestation of systemic drug hypersensitivity," British Journal of Dermatology, vol. 168, no. 5, pp. 1130-1132, 2013.

[9] H. Peyriere, O. Dereure, H. Breton et al., "Variability in the clinical pattern of cutaneous side-effects of drugs with systemic symptoms: does a DRESS syndrome really exist?," British Journal of Dermatology, vol. 155, no. 2, pp. 422-428, 2006.

[10] M. Marchese, M. Leinung, and H. Shawa, "Drug-induced hypersensitivity reaction: a case of simultaneous thyroiditis and fulminant type 1 diabetes," Avicenna Journal of Medicine, vol. 7, no. 2, pp. 67-70, 2017.

[11] Y. Minegaki, Y. Higashida, M. Ogawa, Y. Miyachi, H. Fujii, and K. Kabashima, "Drug-induced hypersensitivity syndrome complicated with concurrent fulminant type 1 diabetes mellitus and Hashimoto's thyroiditis," International Journal of Dermatology, vol. 52, no. 3, pp. 355-357, 2013.

[12] A. Hamasaki, T. Taniguchi, S. Yamane et al., "A case of fulminant type 1 diabetes associated with painless thyroiditis," Diabetes Care, vol. 29, no. 4, pp. 946-947, 2006.

[13] E. M. Singer, K. A. Wanat, and M. A. Rosenbach, "A case of recalcitrant DRESS syndrome with multiple autoimmune sequelae treated with intravenous immunoglobulins," JAMA Dermatology, vol. 149, no. 4, pp. 494-495, 2013.
[14] C. Morita, T Yanase, T Shiohara, and Y Aoyama, “Aggressive treatment in paediatric or young patients with drug-induced hypersensitivity syndrome (DiHS)/drug reaction with eosinophilia and systemic symptoms (DRESS) is associated with future development of type III polyglandular autoimmune syndrome," BMJ Case Reports, vol. 2018, 2018.

[15] Z. Husain, B. Y. Reddy, and R. A. Schwartz, "DRESS syndrome: part I. clinical perspectives," Journal of the American Academy of Dermatology, vol. 68, no. 5, pp. 693.e1-693.e14, 2013.

[16] D.-H. Kim and Y.-I. Koh, "Comparison of diagnostic criteria and determination of prognostic factors for drug reaction with eosinophilia and systemic symptoms syndrome," Allergy, Asthma \& Immunology Research, vol. 6, no. 3, p. 216, 2014.

[17] Y.-C. Chen, H.-C. Chiu, and C.-Y. Chu, "Drug reaction with eosinophilia and systemic symptoms: a retrospective study of 60 cases," Archives of Dermatology, vol. 146, no. 12, pp. 1373-1379, 2010.

[18] W. Y. Ding, C. K. Lee, and S. E. Choon, "Cutaneous adverse drug reactions seen in a tertiary hospital in Johor, Malaysia," International Journal of Dermatology, vol. 49, no. 7 , pp. 834-841, 2010.

[19] S. J. Um, S. K. Lee, Y. H. Kim et al., "Clinical features of druginduced hypersensitivity syndrome in 38 patients," Journal of Investigational Allergology \& Clinical Immunology, vol. 20, no. 7, pp. 556-562, 2010.

[20] P. Wongkitisophon, V. Vachiramon, K. Chanprapaph, and P. Rattanakaemakorn, "Six-year retrospective review of drug reaction with eosinophilia and systemic symptoms," Acta Dermato Venereologica, vol. 92, no. 2, pp. 200-205, 2012.

[21] Z. Sandouk, Z. Alirhayim, D. Khoulani, and S. Hassan, "DRESS syndrome and thrombotic thrombocytopaenic purpura: are they related?," BMJ Case Reports, vol. 2012, no. nov13 1, Article ID bcr2012007558, 2012.

[22] Y.-C. Chen, C.-Y. Chang, Y.-T. Cho, H.-C. Chiu, and C.-Y. Chu, "Long-term sequelae of drug reaction with eosinophilia and systemic symptoms: a retrospective cohort study from Taiwan," Journal of the American Academy of Dermatology, vol. 68, no. 3, pp. 459-465, 2013.

[23] Y. Kano, K. Sakuma, and T. Shiohara, "Sclerodermoid graftversus-host disease-like lesions occurring after drug-induced hypersensitivity syndrome," British Journal of Dermatology, vol. 156, no. 5, pp. 1061-1063, 2007.

[24] N. Aota and T. Shiohara, "Viral connection between drug rashes and autoimmune diseases: how autoimmune responses are generated after resolution of drug rashes," Autoimmunity Reviews, vol. 8, no. 6, pp. 488-494, 2009.

[25] A. Imagawa, T. Hanafusa, T. Awata et al., "Report of the committee of the Japan diabetes society on the research of fulminant and acute-onset type 1 diabetes mellitus: new diagnostic criteria of fulminant type 1 diabetes mellitus (2012)," Journal of Diabetes Investigation, vol. 3, no. 6, pp. 536-539, 2012.

[26] M. Sato, Y. Mizuno, K. Matsuyama et al., "Drug-induced hypersensitivity syndrome followed by subacute thyroiditis," Case Reports in Dermatology, vol. 7, no. 2, pp. 161-165, 2015.

[27] L. Zhang and Y. Zhao, "The regulation of Foxp3 expression in regulatory $\mathrm{CD} 4^{+} \mathrm{CD} 25^{+} \mathrm{T}$ cells: multiple pathways on the road," Journal of Cellular Physiology, vol. 211, no. 3, pp. 590-597, 2007.

[28] R. Takahashi, Y. Kano, Y. Yamazaki, M. Kimishima, Y. Mizukawa, and T. Shiohara, "Defective regulatory T cells in patients with severe drug eruptions: timing of the dysfunction is associated with the pathological phenotype and outcome," 
The Journal of Immunology, vol. 182, no. 12, pp. 8071-8079, 2009.

[29] S. Sakaguchi, "Naturally arising Foxp3-expressing CD $25^{+} \mathrm{CD} 4^{+}$ regulatory $\mathrm{T}$ cells in immunological tolerance to self and nonself," Nature Immunology, vol. 6, no. 4, pp. 345-352, 2005.

[30] L. Liu, Z. Ling, S. Dan, L. Zeyuan, and S. Jie, "Recent findings on fulminant type 1 diabetes," Diabetes/Metabolism Research and Reviews, vol. 34, no. 1, Article ID e2928, 2018.

[31] F. Haseda, A. Imagawa, Y. Murase-Mishiba, J. Terasaki, and T. Hanafusa, "CD4 ${ }^{+} \mathrm{CD} 45 \mathrm{RA}^{-}$FoxP 3 high activated regulatory $\mathrm{T}$ cells are functionally impaired and related to residual insulin-secreting capacity in patients with type 1 diabetes," Clinical \& Experimental Immunology, vol. 173, no. 2, pp. 207-216, 2013.

[32] M. Cutolo, "Autoimmune polyendocrine syndromes," $A u$ toimmunity Reviews, vol. 13, no. 2, pp. 85-89, 2014.

[33] M. Dittmar and G. J. Kahaly, "Polyglandular autoimmune syndromes: immunogenetics and long-term follow-up," The Journal of Clinical Endocrinology \& Metabolism, vol. 88, no. 7, pp. 2983-2992, 2003.

[34] A. W. Michels and P. A. Gottlieb, "Autoimmune polyglandular syndromes," Nature Reviews Endocrinology, vol. 6, no. 5, pp. 270-277, 2010.

[35] M. Dittmar and G. J. Kahaly, "Genetics of the autoimmune polyglandular syndrome type 3 variant," Thyroid, vol. 20, no. 7, pp. 737-743, 2010. 


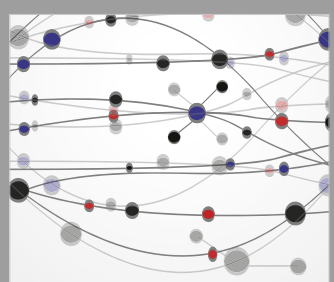

The Scientific World Journal
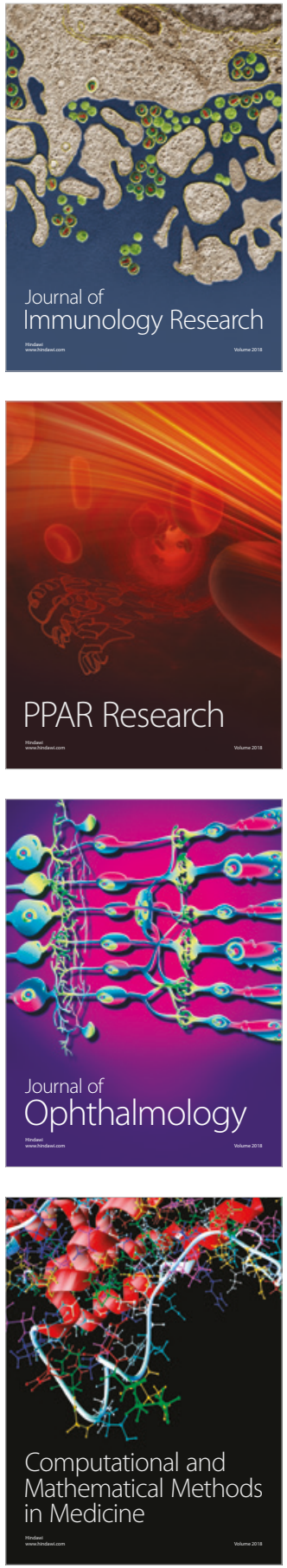

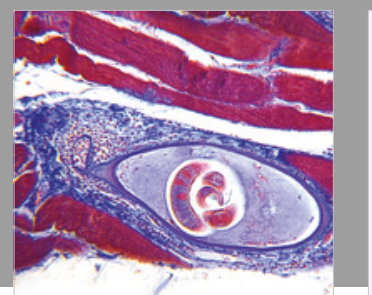

Gastroenterology Research and Practice

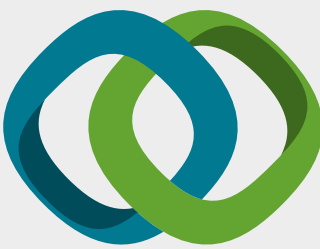

\section{Hindawi}

Submit your manuscripts at

www.hindawi.com
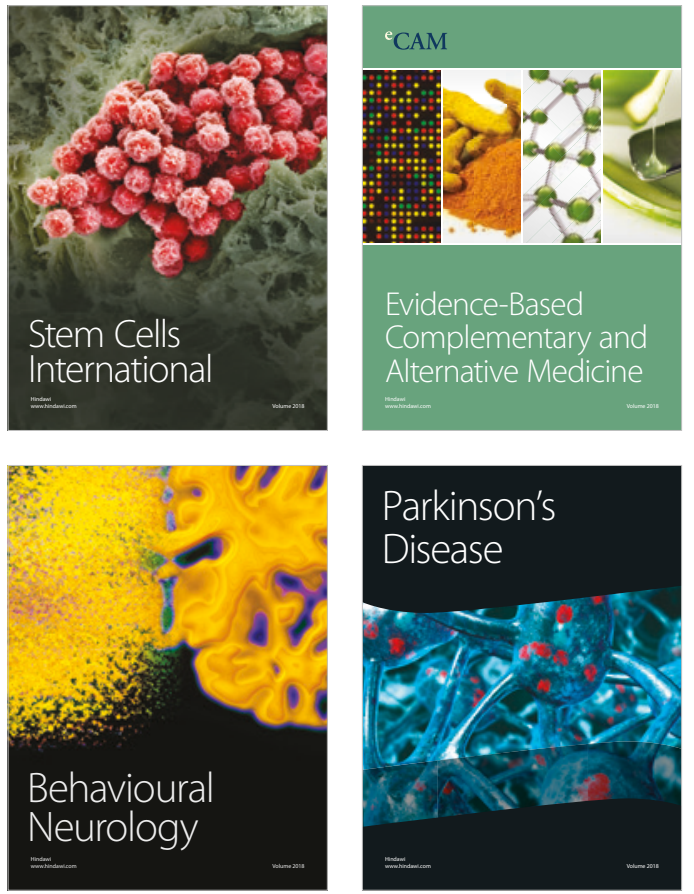

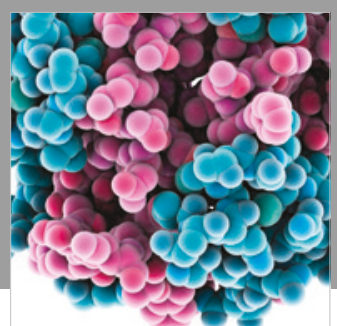

ournal of

Diabetes Research

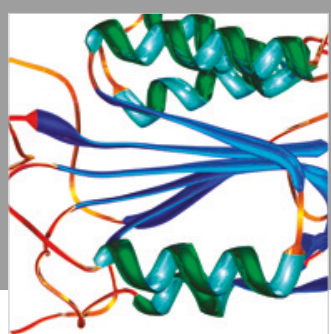

Disease Markers
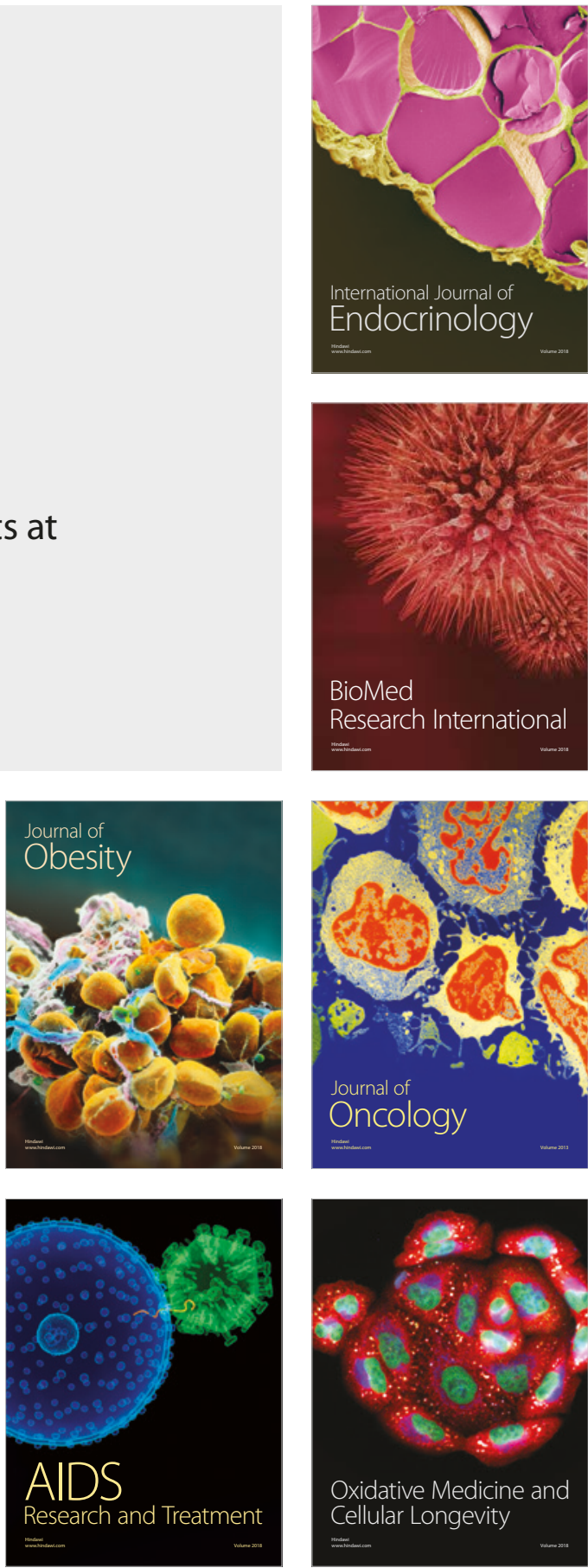